Letter to the Editor

\title{
Oxidative stress and bone mineral density in elderly men: Antioxidant activity of alpha-tocopherol
}

\section{A R T I C L E I N F O}

\section{Keywords}

BMD

Bone

Isoprostanes

Prostaglandins

Osteoporosis

Vitamin E

$\alpha$-Tocopherol

\begin{abstract}
A B S T R A C T
Oxidative stress has recently been identified as a pivotal pathogenetic factor of bone loss in mice, but its importance in humans is not clear. We aimed to investigate the association between urinary 8 -iso-PGF $2 \alpha$ levels, a major $\mathrm{F}_{2}$-isoprostane and a reliable in vivo biomarker of oxidative stress, and bone mineral density (BMD), and to study whether vitamin $\mathrm{E}$ in the form of serum $\alpha$-tocopherol, a scavenger of peroxyl radicals, modifies the association. In 405 men, urinary 8 -iso-PGF $2 \alpha$ and serum $\alpha$-tocopherol were measured at age 77 years and BMD at age 82 years. One SD increase in 8 -iso-PGF $2 \alpha$ corresponded to an approximately $2-4 \%$ decrease in average adjusted BMD values of total body, lumbar spine, and proximal femur (all $P<0.001$ ). Serum $\alpha$-tocopherol levels seemed to modify the association between urinary 8-iso-PGF $2 \alpha$ and BMD. Men with $\alpha$-tocopherol levels below the median combined with high oxidative stress, i.e., 8 -iso-PGF $2 \alpha$ above the median, had 7\% (95\% CI 3-11\%) lower BMD at the lumbar spine and 5\% (95\% CI 2-9\%) lower BMD at the proximal femur. In elderly men high oxidative stress is associated with reduced BMD, which is more pronounced in individuals with low serum levels of the antioxidant vitamin $\mathrm{E}$.
\end{abstract}

(c) 2009 Elsevier Inc. All rights reserved.

\section{Introduction}

Our skeleton is constantly renewed at an average rate of $10 \%$ per year. Osteoporosis is a disease resulting from a decreased renewal of bone, which leads to a fragile skeleton and increased risk of fractures. The etiology of osteoporosis is complex and the fracture risk is influenced both by the genetic constitution and by environmental factors, with lifestyle becoming more important for bone mass and osteoporotic fractures with increasing age $[1,2]$.

Oxidative stress, which presumably increases with age [3], is a condition of excess formation of free radicals either by physiological or pathophysiological processes and states of insufficient antioxidative defense. Free radicals are involved in osteoblastogenesis [4,5], in apoptosis of osteoblasts and osteocytes and in osteoclastogenesis and therefore also in bone resorption as shown in animal and in vitro studies [6]. These experimental data clearly establish a biological link between oxidative stress and bone [7].

A central problem associated with the assessment of free radicalinduced oxidative stress in disease development has been the limitation in existing assay methods for in vivo measurement of free radical generation [8]. $\mathrm{F}_{2}$-Isoprostanes, structural isomers of $\mathrm{PGF}_{2 \alpha}$, are formed during free-radical catalysed peroxidation of arachidonic acid [9]. A major $\mathrm{F}_{2}$-isoprostane, 8 -iso- $\mathrm{PGF}_{2 \alpha}$, is now a well-recognised reliable indicator of oxidative stress in vivo [10-12]. Indeed, we have shown that there is a biochemical link between increased oxidative stress as measured by urinary 8 -iso- $\mathrm{PGF}_{2 \alpha}$ and reduced bone density at some sites in a small population-based study [13]. These results have recently been confirmed and extended in a study showing that serum levels of 8 -iso- $\mathrm{PGF}_{2 \alpha}$ among both hypercholesterolemic patients and hospital-based controls display an inverse correlation with bone formation markers and with bone mineral density (BMD) at the femoral neck but not at the lumbar spine [14]. The paucity of previous human studies examining the association between oxidative stress and BMD and the unstable estimates in these few studies call for new studies with a preferentially larger study size.

Vitamin E scavenges peroxyl radicals [15]. It is a lipid-soluble antioxidant present in plasma and mainly stored in the liver. Plasma concentrations of vitamin $\mathrm{E}$ in humans are tightly regulated and partially genetically determined [16,17] with surprisingly small influential effects of the dietary intake of vitamin E [18]. $\alpha$-Tocopherol is the most abundant form of vitamin $\mathrm{E}$ in human tissues and serum and has the greatest biological activity [15,17]. Administration of $\alpha$ tocopherol has an effect on the isoprostane formation in various experimental models $[19,20]$, but in human studies this effect is only observed at very high levels of supplementation [21].

We aimed in a large prospective study to investigate the association between urinary 8 -iso- PGF $_{2 \alpha}$ levels at 77 years of age and BMD 4 years later. We hypothesised that the conceivable negative influence of oxidative stress measured by urinary 8-iso-PGF $2 \alpha$ on BMD is modified by serum $\alpha$-tocopherol by virtue of its ability to scavenge free radicals. In this context we used a population-based cohort of elderly men to test this hypothesis. 


\section{Materials and methods}

ULSAM -Uppsala Longitudinal Study of Adult Men

The Uppsala Longitudinal Study of Adult Men (http://www. pubcare.uu.se/ULSAM) has been described in detail elsewhere [22,23]. Briefly, from 1970 to 1973, all 2841 men born in 19201924 and living in the municipality of Uppsala, Sweden, were invited to participate in a health survey. A total of 2322 men ( $82 \%$ of those invited), 49 to 51 years of age (age 50), agreed to participate. Four more evaluations have been performed: at $60(n=1,860), 70$ $(n=1,221), 77(n=839)$, and 82 years of age $(n=530)$. The fourth evaluation at 77 years of age, when urine was collected over $24 \mathrm{~h}$, forms the baseline for the present study. Both urine and plasma from the fourth evaluation were stored at $-70^{\circ} \mathrm{C}$ until analyses. Urinary 8-iso- PGF $_{2 \alpha}$ and 15-keto-dihydro- $\mathrm{PGF}_{2 \alpha}$ levels (an inflammatory response indicator) were available for 706 (84\%) of these men. At each investigation participants provided blood samples and answered a questionnaire regarding medical history, lifestyle habits, and regular medication. The study was approved by the Ethics Committee of Uppsala University. All participants gave written informed consent.

\section{Assay of $F_{2}$-isoprostanes (oxidative stress indicator)}

Urinary samples were analysed for 8-iso- $\mathrm{PGF}_{2 \alpha}$, a major $\mathrm{F}_{2^{-}}$ isoprostane, by a specific and validated radioimmunoassay at our laboratory as described in detail elsewhere [24]. The detection limit of the 8 -iso- $\mathrm{PGF}_{2 \alpha}$ assay was $23 \mathrm{pmol} / \mathrm{L}$. The urinary levels of 8 -iso$\mathrm{PGF}_{2 \alpha}$ were adjusted for urinary creatinine concentration (UCC). The intraassay coefficient of variation (CV) was $14.5 \%$ at low concentrations and $12.2 \%$ at high concentrations.

\section{5-Keto-dihydro-PGF $F_{2 \alpha}$ (inflammatory response indicator)}

Urinary samples were analysed for 15-keto-dihydro- $\mathrm{PGF}_{2 \alpha}$, a major metabolite of primary $\mathrm{PGF}_{2 \alpha}$, by a specific and validated radioimmunoassay at our laboratory as described previously [25]. The urinary levels of 15-keto-dihydro- PGF $_{2 \alpha}$ were adjusted for UCC. The intraassay CV was $12.2 \%$ at low concentrations and $14.0 \%$ at high concentrations.

\section{Serum $\alpha$-tocopherol}

Serum $\alpha$-tocopherol was analysed using high performance liquid chromatography (HPLC) and fluorescence detection with a Hitachi pump and LiChrospher $100 \mathrm{NH} 2250 \times 4-\mathrm{mm}$ column [26]. The serum tocopherol levels were adjusted for the sum of the total serum cholesterol and triglyceride concentration (tocopherol/ (cholesterol+triglyceride)) [27]. The intraassay CV for the method was $4.5 \%$.

\section{Dual-energy X-ray absorptiometry (DXA)}

At the fifth ULSAM investigation at age 82, on average 4 years after the analysis of oxidative stress levels by 8 -iso- $\mathrm{PGF}_{2 \alpha}, 507$ men agreed to undergo measurements of BMD of the total body, proximal femur, and lumbar spine (vertebrae L2-L4), as well as total lean and fat mass by DXA (DPX Prodigy, Lunar Corp., Madison, WI, USA). When applicable, both extremities were used in the calculation. By triple measurements in 15 participants, the precision error of the DXA measurements in our laboratory has been calculated to be between 0.8 and $1.5 \%$ for BMD depending on site and between 0.7 and $1.6 \%$ for bone areas. Total fat mass had a precision error of $1.5 \%$ and total lean mass $1.0 \%$.
Totally, 405 men from the general population underwent measurement for both 8 -iso-PGF $2 \alpha$ and serum $\alpha$-tocopherol at age 77 years and they had their BMD measured by DXA at age 82 years. These men constitute the study base for the present investigation.

\section{Statistical analysis}

All statistical calculations were performed using SAS (SAS 9.1, SAS Institute, Cary, NC, USA). We used standard linear regression models to examine the relationship between 8 -iso- $\mathrm{PGF}_{2 \alpha}$, as expressed per standard deviation increase in urine values, and BMD. A normal probability plot of the residuals indicated no deviation from a linear pattern, as also indicated by Shapiro-Wilk tests with $w \geq 0.99$. The variables were thus kept in their original continuous form. A potential nonlinear association was examined by introduction of a quadratic term of 8 -iso-PGF $2 \alpha$ in the regression model. Smoking, obesity, and type 2 diabetes could be regarded as confounders but their effect on BMD may also be mediated by oxidative stress. Therefore, two models were used in the analyses: an age-adjusted model, including age at entry and end of follow-up (at time of the bone scan), and a multivariable model that included, in addition to age, counting height and weight (both at baseline and study end), total fat mass, total lean mass, 15 -keto-dihydro- $\mathrm{PGF}_{2 \alpha} /$ creatinine ratio (as a valid measure on degree of inflammation) [25], and the following categorical variables at both baseline and at end of follow-up: smoking status (never, former, current), leisure physical activity (low, intermediate, high), hypertension (yes/no), current oral cortisone use (yes/no), and diabetes mellitus (yes/no). We additionally had the possibility of adjusting our estimates for plasma vitamin D levels, calcium intake, vitamin D intake, vitamin C intake, alcohol intake, and calcium and vitamin D supplemental use. These variables were measured at a prior investigation, at age 71 years. Dietary and supplemental intakes were recorded in a 7-day dietary record. Nutrients were calculated with the use of data from the Swedish National Food Administration [28]. Plasma 25-hydroxyvitamin D was determined with high-pressure liquid chromatography (HPLC) atmospheric pressure chemical ionisation (APCI) mass spectrometry (MS) at Vitas, Oslo, Norway. None of these covariates influenced our estimates and they were therefore not included in the final multivariable model.

Exposure combinations of $\alpha$-tocopherol and 8 -iso-PGF $2 \alpha$ were constructed because we postulated that $\alpha$-tocopherol modulated the association between 8-iso-PGF $2 \alpha$ and BMD. Forming four categories, levels below or above the median of $\alpha$-tocopherol were combined with levels below or above the median of 8 -iso- $\mathrm{PGF}_{2 \alpha}$.

\section{Results}

Descriptive characteristics of the participants at baseline, at an average age of 77.5 years, by combinations of low (below the median) and high levels (above the median) of urinary 8-iso- $\mathrm{PGF}_{2 \alpha}$ and serum $\alpha$-tocopherol are displayed in Table 1 . There were small differences between the categories in baseline values. Nevertheless, men with high $\alpha$-tocopherol values and low oxidative stress values had a lower prevalence of diabetes mellitus.

As shown in Table 2, urinary 8-iso- $\mathrm{PGF}_{2 \alpha}$ levels were negatively associated with total body, proximal femur, and lumbar spine BMD. One SD increase in 8-iso- $\mathrm{PGF}_{2 \alpha}$ levels corresponded to a decrease in average BMD values of about $2-4 \%$ depending on site. The parameter estimates were not substantially altered after multivariable adjustment. We did not discover any threshold effects because inclusion of a quadratic term of 8 -iso- $\mathrm{PGF}_{2 \alpha}$ was far from statistically significant at all sites $(P>0.7)$.

Serum $\alpha$-tocopherol levels seemed to modify the association between urinary 8 -iso-PGF $2 \alpha$ and BMD (Fig. 1 ). Elderly men with $\alpha$ tocopherol levels below the median combined with a high degree of oxidative stress, i.e., 8-iso- PGF $_{2 \alpha}$ levels above the median, had 7\% (95\% 
Table 1

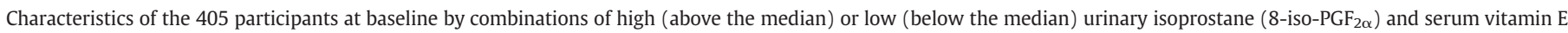
( $\alpha$-tocopherol)

\begin{tabular}{|c|c|c|c|c|}
\hline \multirow[t]{2}{*}{ Baseline data (at age 77 years) } & $\begin{array}{l}\text { High serum vitamin } \mathrm{E} \text {, } \\
\text { low urine isoprostane }\end{array}$ & $\begin{array}{l}\text { Low serum vitamin } \mathrm{E} \text {, } \\
\text { low urine isoprostane }\end{array}$ & $\begin{array}{l}\text { High serum vitamin } \mathrm{E} \text {, } \\
\text { high urine isoprostane }\end{array}$ & $\begin{array}{l}\text { Low serum vitamin } \mathrm{E} \text {, } \\
\text { high urine isoprostane }\end{array}$ \\
\hline & $n=112$ & $\overline{n=91}$ & $n=92$ & $n=110$ \\
\hline \multicolumn{5}{|l|}{ 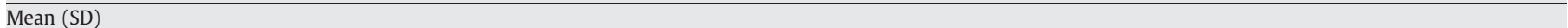 } \\
\hline Age (years) & $77.5(0.8)$ & $77.4(0.8)$ & $77.4(0.7)$ & $77.5(0.7)$ \\
\hline Weight (kg) & $77.6(10.4)$ & $80.5(11.2)$ & $78.9(11.8)$ & $80.3(11.4)$ \\
\hline Height $(\mathrm{cm})$ & $173.0(5.3)$ & $174.3(5.3)$ & $174.1(4.8)$ & $173.8(6.3)$ \\
\hline Body mass index $\left(\mathrm{kg} / \mathrm{m}^{2}\right)$ & $25.9(3.1)$ & $26.4(3.3)$ & $26.0(3.6)$ & $26.5(3.1)$ \\
\hline Urinary 8 -iso- $\mathrm{PGF}_{2 \alpha}(\mathrm{nmol} / \mathrm{mmol}$ creatinine $)$ & $0.14(0.03)$ & $0.14(0.03)$ & $0.26(0.09)$ & $0.26(0.08)$ \\
\hline Urinary 15 -keto-dihydro- $\mathrm{PGF}_{2 \alpha}$ (nmol/mmol creatinine) & $0.27(0.13)$ & $0.27(0.09)$ & $0.35(0.21)$ & $0.34(0.18)$ \\
\hline Serum $\alpha$-tocopherol ( $\mu \mathrm{mol} / \mathrm{mmol}$, lipid-corrected $)$ & $4.2(0.6)$ & $3.3(0.2)$ & $4.1(0.3)$ & $3.3(0.3)$ \\
\hline \multicolumn{5}{|l|}{ Number (percent) } \\
\hline \multicolumn{5}{|l|}{ Smoking status } \\
\hline Never smoker & $93(83.1)$ & $76(83.5)$ & $81(88.0)$ & $91(82.8)$ \\
\hline Former smoker & $11(9.8)$ & $11(12.1)$ & $7(7.6)$ & $13(11.8)$ \\
\hline Current smoker & $8(7.1)$ & $4(4.4)$ & $4(4.4)$ & $6(5.4)$ \\
\hline \multicolumn{5}{|l|}{ Physical activity } \\
\hline Low & $6(5.4)$ & $3(3.3)$ & $8(8.7)$ & $10(9.1)$ \\
\hline Medium & $36(32.1)$ & $32(35.2)$ & $31(33.7)$ & $33(8.1)$ \\
\hline High & $70(62.5)$ & $56(61.5)$ & $53(57.6)$ & $67(60.9)$ \\
\hline Diabetes & $3(2.7)$ & $10(11.0)$ & $15(16.3)$ & $19(17.3)$ \\
\hline Hypertension & $52(46.4)$ & $26(28.6)$ & $46(50.0)$ & $45(40.9)$ \\
\hline Use of oral cortisone & $3(2.7)$ & $2(2.2)$ & $2(2.2)$ & $4(3.7)$ \\
\hline \multicolumn{5}{|l|}{ Mean (SD) } \\
\hline \multicolumn{5}{|l|}{ Dietary intake (at age 71 years) } \\
\hline Vitamin C (mg/day) & $46(23)$ & $60(50)$ & $62(40)$ & $53(34)$ \\
\hline Beta carotene (mg/day) & $1.5(1.0)$ & $1.6(1.4)$ & $1.7(1.2)$ & $1.9(1.6)$ \\
\hline Vitamin E (mg/day) & $6.5(2.3)$ & $6.9(3.0)$ & $6.2(2.1)$ & $6.5(2.4)$ \\
\hline Vitamin D ( $\mu \mathrm{g} /$ day) & $5.9(1.9)$ & $6.1(2.5)$ & $5.9(2.5)$ & $5.9(2.0)$ \\
\hline Plasma vitamin D (nmol/L. At age 71 years) & $71.9(21.0)$ & $68.4(17.9)$ & 65.9 (17.9) & 70.7 (16.6) \\
\hline
\end{tabular}

CI 3-11\%) lower BMD at the lumbar spine and 5\% (95\% CI 2-9\%) lower BMD at the proximal femur compared with the other participants. There was statistical interaction between 8 -iso-PGF $2 \alpha$ and $\alpha$-tocopherol for both the outcomes BMD at the lumbar spine $(P=0.04)$ and BMD at the proximal femur $(P=0.04)$.

No association was observed between serum $\alpha$-tocopherol and BMD at our measured sites (Table 3). Using Pearson's correlation coefficient, we also found only a weak correlation between urinary 8iso-PGF $2 \alpha$ and serum $\alpha$-tocopherol $(r=0.08, P=0.04)$.

\section{Discussion}

The main finding of this study is the negative association among the oxidative stress marker urinary $\mathrm{F}_{2}$-isoprostane and BMD at the lumbar spine, the proximal femur, and of the total body, and that the association is further dependent on serum vitamin $\mathrm{E}$ level. We found only a modest association between urinary 8 -iso- $\mathrm{PGF}_{2 \alpha}$ and serum $\alpha$ -

Table 2

Association between bone mineral density (BMD) and 1 standard deviation increase in urinary 8 -iso- $\mathrm{PGF}_{2 \alpha}$

\begin{tabular}{|c|c|c|c|c|c|c|}
\hline \multirow[t]{2}{*}{ Variable } & \multicolumn{3}{|c|}{ Age-adjusted model } & \multicolumn{3}{|c|}{ Multivariable model $^{\mathrm{a}}$} \\
\hline & $\begin{array}{l}\text { Parameter } \\
\text { estimate }\end{array}$ & $\begin{array}{l}95 \% \mathrm{CI} \\
\text { for } \beta\end{array}$ & $P$ value & $\begin{array}{l}\text { Parameter } \\
\text { estimate }\end{array}$ & $\begin{array}{l}95 \% \mathrm{CI} \\
\text { for } \beta\end{array}$ & $P$ value \\
\hline $\begin{array}{l}\text { BMD total body } \\
\left(\mathrm{g} / \mathrm{cm}^{2}\right)\end{array}$ & -0.018 & $\begin{array}{l}-0.029 \\
-0.008\end{array}$ & 0.0006 & -0.017 & $\begin{array}{l}-0.027 \\
-0.008\end{array}$ & 0.0005 \\
\hline $\begin{array}{l}\text { BMD proximal } \\
\text { femur }\left(\mathrm{g} / \mathrm{cm}^{2}\right)\end{array}$ & -0.031 & $\begin{array}{l}-0.050 \\
-0.013\end{array}$ & 0.0009 & -0.031 & $\begin{array}{l}-0.048 \\
-0.013\end{array}$ & 0.0008 \\
\hline $\begin{array}{l}\text { BMD lumbar } \\
\text { spine }\left(\mathrm{g} / \mathrm{cm}^{2}\right)\end{array}$ & -0.048 & $\begin{array}{l}-0.073 \\
-0.022\end{array}$ & 0.0002 & -0.045 & $\begin{array}{l}-0.069 \\
-0.019\end{array}$ & 0.0007 \\
\hline
\end{tabular}

a Model including the continuous variables age at entry and end of follow-up (at time of the bone scan), height and weight (both at baseline and at study end), total fat mass, total lean mass, 15-keto-dihydro- $\mathrm{PGF}_{2 \alpha} /$ creatinine ratio, and the following categorical variables both at baseline and at end of follow-up: smoking status (never, former current), leisure physical activity (low, intermediate, high), cortisone use (yes/no), and diabetes (yes/no) at baseline. tocopherol. This can be explained theoretically both by the vitamin's local cellular effect of stabilising membrane phospholipids from damage by free radicals [17], with no or minor direct influence on systemic isoprostane levels at physiological levels of the vitamin [29], and by the tight regulation of serum $\alpha$-tocopherol [30].

Oxidative stress may increase bone resorption through activation of nuclear factor-kappa $\beta$ (NF-K $\beta$ ) [32,33], which is part of the RANKLOPG axis [31] that regulates osteoclast differentiation and thus bone resorption and remodeling. The immense significance of NF-K $\beta$ in osteoclastogenesis and bone turnover has recently been revealed by the discovery of osteopetrosis in mice lacking NF- $\kappa \beta$ [34] and the identification of receptor activator of NF-K $\beta$-(RANK), the RANK ligand, and the decoy receptor osteoprotegerin [35]. Of special interest in association with the present study, NF- $\beta \beta$ activates release of 8isoprostane from fetal membranes in vitro. When these were treated with the potent free radical scavenger $\mathrm{N}$-acetylcysteine, the release was inhibited [36]. Oxidative stress is a potential link between osteoporosis and known risk factors such as heart failure [37], smoking [38], and hypertension [39] and this link may at least partly be mediated by NF-K $\beta$ with its important role in modulating the expression of many genes involved in cell proliferation, differentiation, apoptosis, stress response, cell signalling transduction, inflammation, and other pathophysiological processes. Oxidative stress may also influence osteoblastogenesis and bone formation, where the Wnt- $\beta$-catenin pathway has emerged as a central regulator [40]. Recently, it was demonstrated that oxidative stress antagonises the skeletal effects of Wnt- $\beta$-catenin in vitro [4]. Thus, in summary, bone resorption can be activated and bone formation deactivated by oxidative stress.

Previously we suggested a biochemical link between increased oxidative stress, as measured by urinary $\mathrm{F}_{2}$-isoprostanes, and reduced BMD in humans [13]. In that smaller study involving 100 participants we showed that higher levels of urinary 8 -iso- $\mathrm{PGF}_{2 \alpha}$ were related to lower BMD at peripheral sites of the skeleton. Our present investigation corroborates these earlier findings and adds to current knowledge 


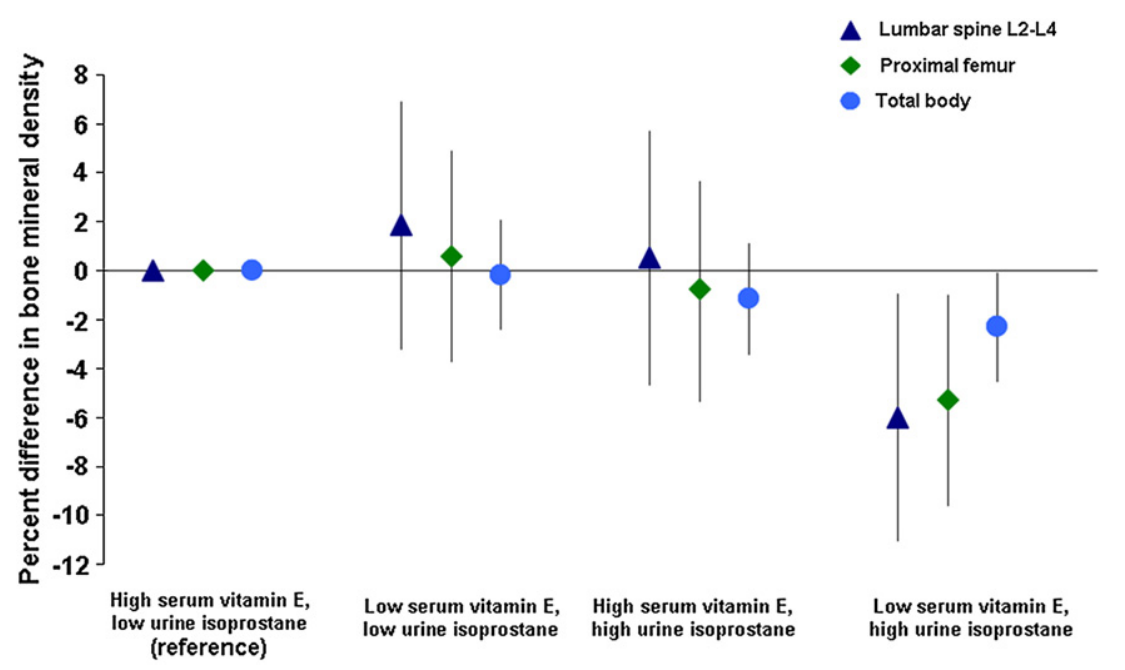

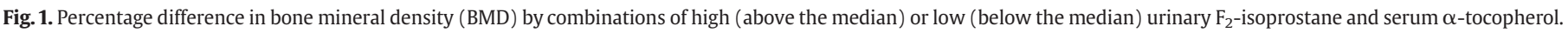

by the inclusion of a larger number of participants, analysis of men only and participants of the same age, inclusion of several additional potential covariates in our models, and a clear negative association between urinary 8 -iso- $\mathrm{PGF}_{2 \alpha}$ and BMD at all measured sites. Our investigation was performed within a well-established cohort of elderly men, the ULSAM. The results were independent of smoking, body composition, and cyclooxygenase-mediated inflammation status as measured by 15 -keto-dihydro-PGF $2 \alpha$ in urine. In a diabetes mellitus rat model, 8-hydroxydeoxyguanosine, which is an oxidative stress marker, was remarkably elevated and associated with low turnover of bone [41]. Even though there was a higher prevalence of diabetes among those with high 8 -iso- $\mathrm{PGF}_{2 \alpha}$ (Table 1 ), our estimates were unaffected after adjustment for the diagnosis of diabetes mellitus. In a study from Italy [14], serum levels of 8 -iso-PGF $2 \alpha$ correlated negatively to lumbar spine and femoral neck BMD. A negative influence was also found between bone formation markers and oxidative stress, whereas bone resorption measured as carboxyterminal cross-linking telopeptide of type I collagen (CTX-I) did not display an association with serum 8-iso-PGF $2 \alpha$. These findings indicate less of a role for the RANK-RANKL-OPG axis as a mediator of the negative influence of oxidative stress on bone. Furthermore, 8-isoPGF $_{2 \alpha}$ had no association with serum levels of RANKL and OPG. However, these modulators of bone resorption primarily exert their actions by paracrine effects on bone cells and thus the serum levels might not mirror these local activities.

Our study also extends previous investigations by the possibility to determine the modifying influence of $\alpha$-tocopherol, a potent

Table 3

Association between bone mineral density (BMD) and 1 standard deviation increase in serum $\alpha$-tocopherol

\begin{tabular}{|c|c|c|c|c|c|c|}
\hline \multirow[t]{2}{*}{ Variable } & \multicolumn{3}{|c|}{ Age-adjusted model } & \multicolumn{3}{|c|}{ Multivariable model $^{\mathrm{a}}$} \\
\hline & $\begin{array}{l}\text { Parameter } \\
\text { estimate }\end{array}$ & $\begin{array}{l}95 \% \mathrm{CI} \\
\text { for } \beta\end{array}$ & $P$ value & $\begin{array}{l}\text { Parameter } \\
\text { estimate }\end{array}$ & $\begin{array}{l}95 \% \mathrm{CI} \\
\text { for } \beta\end{array}$ & $P$ value \\
\hline $\begin{array}{l}\text { BMD total body } \\
\left(\mathrm{g} / \mathrm{cm}^{2}\right)\end{array}$ & 0.001 & $\begin{array}{c}-0.012 \\
0.010\end{array}$ & 0.86 & 0.001 & $\begin{array}{c}-0.009 \\
0.011\end{array}$ & 0.86 \\
\hline $\begin{array}{l}\text { BMD proximal } \\
\text { femur }\left(\mathrm{g} / \mathrm{cm}^{2}\right)\end{array}$ & 0.000 & $\begin{array}{c}-0.018 \\
0.017\end{array}$ & 0.98 & 0.006 & $\begin{array}{c}-0.011 \\
0.023\end{array}$ & 0.48 \\
\hline $\begin{array}{l}\text { BMD lumbar } \\
\text { spine }\left(\mathrm{g} / \mathrm{cm}^{2}\right)\end{array}$ & 0.003 & $\begin{array}{c}-0.024 \\
0.030\end{array}$ & 0.84 & 0.002 & $\begin{array}{c}-0.025 \\
0.029\end{array}$ & 0.88 \\
\hline
\end{tabular}

a Model including the continuous variables age at entry and end of follow-up (at time of the bone scan), height and weight (both at baseline and at study end), total fat mass, total lean mass, 15-keto-dihydro- $\mathrm{PGF}_{2 \alpha} /$ creatinine ratio, and the following categorical variables at both baseline and at end of follow-up: smoking status (never, former, current), leisure physical activity (low, intermediate, high), cortisone use (yes/no), and diabetes (yes/no) at baseline. scavenger of reactive oxygen species, on the association between 8iso-PGF $2 \alpha$ and BMD. Trolox, a water-soluble vitamin $\mathrm{E}$ analogue, prevents osteoclast formation and bone loss by inhibiting both RANKL induction in osteoblasts and c-Fos expression in osteoclast precursors [42]. In an earlier study we established that an inadequate dietary intake of antioxidants increases considerably the risk of hip fracture in current smokers, whereas current smokers with a more adequate intake of antioxidants appear to have a fracture risk similar to that observed among never smokers [43], supporting the theory that oxidative stress has important effects on bone in man. A low intake of antioxidants has also recently been associated with an increased hip fracture risk in women $[44,45]$. It has as well been shown that osteoporotic women have lower serum antioxidant levels compared with controls [46], and that higher intake of antioxidants may suppress bone resorption [47] and retard bone loss in some [48-51] but not all [52] observational studies.

We acknowledge some additional strengths but also limitations. A free radical-mediated arachidonic acid oxidation leads to the formation of isoprostanes in vivo, and 8-iso- $\mathrm{PGF}_{2 \alpha}$ is currently recognized as the gold marker determinant of in vivo oxidative stress in both humans and animals [53,54]. The measurement of 8iso- $\mathrm{PGF}_{2 \alpha}$ in urine is considered to be more appropriate than in plasma when the basal levels are to be evaluated due to less fluctuation at higher basal levels in urine than in plasma [10]. In addition to having a valid measure of the exposure, our study has a favorable design regarding homogeneous age, gender, and ethnicity but has as such also the disadvantage of limited generalizability to other ethnic groups and women. Further, we studied survivors to the age of 82 years. These men had had a healthier lifestyle than the nonsurvivors of the cohort [55] which is also indicated by the low proportion of smokers and sedentary men among those who attained the DXA measurement at age 82 years. A possible healthy cohort effect would not lead to false positive results but instead tend to reduce the strength of the association between high oxidative stress and reduced BMD. Bone is constantly renewed at an average rate of $10 \%$ per year. The measurement of BMD was performed on average 4 years after the 24-h urine collection used for 8 -iso- $\mathrm{PGF}_{2 \alpha}$ analysis. The optimal interval between exposure and outcome in this case is not known but given the rate of bone remodeling an induction period of 4 years seems to be reasonable.

In conclusion, this study demonstrates an association between isoprostane formation and reduced bone mineral density in a large well-characterized cohort. This association was of particular importance among men with low levels of serum $\alpha$-tocopherol. 


\section{Acknowledgment}

Supported by grants from the Swedish Research Council.

\section{References}

[1] Michaëlsson, K.; Melhus, H.; Ferm, H.; Ahlbom, A.; Pedersen, N. L. Genetic liability to fractures in the elderly. Arch. Intern. Med. 165:1825-1830; 2005.

[2] Slemenda, C. W.; Christian, J. C.; Williams, C. J.; Norton, J. A.; Johnston Jr, C. C. Genetic determinants of bone mass in adult women: a reevaluation of the twin model and the potential importance of gene interaction on heritability estimates. J. Bone Miner. Res. 6:561-567; 1991.

[3] Golden, T. R.; Hinerfeld, D. A.; Melov, S. Oxidative stress and aging: beyond correlation. Aging Cell 1:117-123; 2002.

[4] Almeida, M.; Han, L.; Martin-Millan, M.; O'Brien, C. A.; Manolagas, S. C. Oxidative stress antagonizes Wnt signaling in osteoblast precursors by diverting betacatenin from T cell factor-to forkhead box O-mediated transcription. J. Biol. Chem. 282:27298-27305; 2007.

[5] Jilka, R. L.; Weinstein, R. S.; Parfitt, A. M.; Manolagas, S. C. Quantifying osteoblast and osteocyte apoptosis: challenges and rewards. J. Bone Miner. Res. 22: $1492-1501 ; 2007$.

[6] Garrett, I. R.; Boyce, B. F.; Oreffo, R. O.; Bonewald, L.; Poser, J.; Mundy, G. R. Oxygenderived free radicals stimulate osteoclastic bone resorption in rodent bone in vitro and in vivo. J. Clin. Invest. 85:632-639; 1990.

[7] Manolagas, S. C.; Almeida, M. Gone with the Wnts: beta-catenin, T-cell factor, forkhead box $\mathrm{O}$, and oxidative stress in age-dependent diseases of bone, lipid, and glucose metabolism. Mol. Endocrinol. 21:2605-2614; 2007.

[8] Halliwell, B.; Grootveld, M. The measurement of free radical reactions in humans. Some thoughts for future experimentation. FEBS Lett. 213:9-14; 1987.

[9] Morrow, J. D.; Hill, K. E.; Burk, R. F.; Nammour, T. M.; Badr, K. F.; Roberts, L. J. 2nd. A series of prostaglandin F2-like compounds are produced in vivo in humans by a non-cyclooxygenase, free radical-catalyzed mechanism. Proc. Natl. Acad. Sci. USA 87:9383-9387; 1990.

[10] Basu, S. F2-isoprostanes in human health and diseases: from molecular mechanisms to clinical implications. Antioxid. Redox Signal. 10:1405-1434; 2008.

[11] Kadiiska, M. B.; Gladen, B. C.; Baird, D. D.; Graham, L. B.; Parker, C. E.; Ames, B. N.; Basu, S.; Fitzgerald, G. A.; Lawson, J. A.; Marnett, L. J.; Morrow, J. D.; Murray, D. M.; Plastaras, J.; Roberts II, L. J.; Rokach, J.; Shigenaga, M. K.; Sun, J.; Walter, P. B.; Tomer, K. B.; Barrett, J. C.; Mason, R. P. Biomarkers of oxidative stress study. III. Effects of the nonsteroidal anti-inflammatory agents indomethacin and meclofenamic acid on measurements of oxidative products of lipids in $\mathrm{CCl} 4$ poisoning. Free Radic. Biol. Med. 38:711-718; 2005.

[12] Morrow, J. D. The isoprostanes: their quantification as an index of oxidant stress status in vivo. Drug Metab. Rev. 32:377-385; 2000.

[13] Basu, S.; Michaëlsson, K.; Olofsson, H.; Johansson, S.; Melhus, H. Association between oxidative stress and bone mineral density. Biochem. Biophys. Res. Commun. 288:275-279; 2001.

[14] Mangiafico, R. A.; Malaponte, G.; Pennisi, P.; Li Volti, G.; Trovato, G.; Mangiafico, M.; Bevelacqua, Y.; Mazza, F.; Fiore, C. E. Increased formation of 8-isoprostaglandin $\mathrm{F}$ (2alpha) is associated with altered bone metabolism and lower bone mass in hypercholesterolaemic subjects. J. Intern. Med. 261:587-596; 2007.

[15] Fairfield, K. M.; Fletcher, R. H. Vitamins for chronic disease prevention in adults: scientific review. JAMA 287:3116-3126; 2002.

[16] Gueguen, S.; Leroy, P.; Gueguen, R.; Siest, G.; Visvikis, S.; Herbeth, B. Genetic and environmental contributions to serum retinol and alpha-tocopherol concentrations: the Stanislas Family Study. Am. J. Clin. Nutr. 81:1034-1044; 2005.

[17] Traber, M. G. Vitamin E regulatory mechanisms. Annu. Rev. Nutr. 27:347-362; 2007.

[18] McNaughton, S. A.; Marks, G. C.; Gaffney, P.; Williams, G.; Green, A. Validation of a food-frequency questionnaire assessment of carotenoid and vitamin E intake using weighed food records and plasma biomarkers: the method of triads model. Eur. J. Clin. Nutr. 59:211-218; 2005.

[19] Pratico, D.; Tangirala, R. K.; Rader, D. J.; Rokach, J.; FitzGerald, G. A.; Vitamin, E. suppresses isoprostane generation in vivo and reduces atherosclerosis in ApoEdeficient mice. Nat. Med. 4:1189-1192; 1998

[20] Sodergren, E.; Cederberg, J.; Basu, S.; Vessby, B.; Vitamin, E. supplementation decreases basal levels of $F(2)$-isoprostanes and prostaglandin $f(2 a l p h a)$ in rats. J. Nutr. 130:10-14; 2000.

[21] Roberts II, L. J.; Oates, J. A.; Linton, M. F.; Fazio, S.; Meador, B. P.; Gross, M. D.; Shyr Y.; Morrow, J. D. The relationship between dose of vitamin E and suppression of oxidative stress in humans. Free Radic. Biol. Med. 43:1388-1393; 2007.

[22] Michaëlsson, K.; Lithell, H.; Vessby, B.; Melhus, H. Serum retinol levels and the risk of fracture. N. Engl. J. Med. 348:287-294; 2003.

[23] Olofsson, H.; Byberg, L.; Mohsen, R.; Melhus, H.; Lithell, H.; Michaëlsson, K. Smoking and the risk of fracture in older men. J. Bone Miner. Res. 20:1208-1215; 2005.

[24] Basu, S. Radioimmunoassay of 8-iso-prostaglandin F2alpha: an index for oxidative injury via free radical catalysed lipid peroxidation. Prostaglandins Leukot. Essent. Fatty Acids 58:319-325; 1998

[25] Basu, S. Radioimmunoassay of 15-keto-13,14-dihydro-prostaglandin F2alpha: an index for inflammation via cyclooxygenase catalysed lipid peroxidation. Prostaglandins Leukot. Essent. Fatty Acids 58:347-352; 1998.

[26] Ohrvall, M.; Tengblad, S.; Vessby, B. Lower tocopherol serum levels in subjects with abdominal adiposity. J. Intern. Med. 234:53-60; 1993.
[27] Thurnham, D. I.; Davies, J. A.; Crump, B. J.; Situnayake, R. D.; Davis, M. The use of different lipids to express serum tocopherol: lipid ratios for the measurement of vitamin E status. Ann. Clin. Biochem. 23 (Pt 5):514-520; 1986.

[28] Smedman, A. E.; Gustafsson, I. B.; Berglund, L. G.; Vessby, B. O. Pentadecanoic acid in serum as a marker for intake of milk fat: relations between intake of milk fat and metabolic risk factors. Am. J. Clin. Nutr. 69:22-29; 1999.

[29] Meagher, E. A.; Barry, O. P.; Lawson, J. A.; Rokach, J.; FitzGerald, G. A. Effects of vitamin $\mathrm{E}$ on lipid peroxidation in healthy persons. JAMA 285:1178-1182; 2001.

[30] Traber, M. G.; Atkinson, J.; Vitamin, E. antioxidant and nothing more. Free Radic. Biol. Med. 43:4-15; 2007.

[31] Vega, D.; Maalouf, N. M.; Sakhaee, K. Clinical review. The role of receptor activator of nuclear factor-kappaB (RANK)/RANK ligand/osteoprotegerin: clinical implications. J. Clin. Endocrinol. Metab. 92:4514-4521; 2007.

[32] Schreck, R.; Baeuerle, P. A. A role for oxygen radicals as second messengers. Trends Cell Biol. 1:39-42; 1991.

[33] Schreck, R.; Rieber, P.; Baeuerle, P. A. Reactive oxygen intermediates as apparently widely used messengers in the activation of the NF-kappa B transcription factor and HIV-1. EMBO J. 10:2247-2258; 1991.

[34] Suda, N.; Morita, I.; Kuroda, T.; Murota, S. Participation of oxidative stress in the process of osteoclast differentiation. Biochim. Biophys. Acta 1157:318-323; 1993.

[35] Iotsova, V.; Caamano, J.; Loy, J.; Yang, Y.; Lewin, A.; Bravo, R. Osteopetrosis in mice lacking NF-kappaB1 and NF-kappaB2. Nat. Med. 3:1285-1289; 1997.

[36] Lappas, M.; Permezel, M.; Rice, G. E. N-Acetyl-cysteine inhibits phospholipid metabolism, proinflammatory cytokine release, protease activity, and nuclear factor-kappaB deoxyribonucleic acid-binding activity in human fetal membranes in vitro. J. Clin. Endocrinol. Metab. 88:1723-1729; 2003.

[37] van Diepen, S.; Majumdar, S. R.; Bakal, J. A.; McAlister, F. A.; Ezekowitz, J. A. Heart failure is a risk factor for orthopedic fracture: a population-based analysis of 16,294 patients. Circulation 118:1946-1952; 2008.

[38] Law, M. R.; Hackshaw, A. K. A meta-analysis of cigarette smoking, bone minera density and risk of hip fracture: recognition of a major effect. BMJ 315:841-846; 1997.

[39] Cappuccio, F. P.; Meilahn, E.; Zmuda, J. M.; Cauley, J. A. High blood pressure and bone-mineral loss in elderly white women: a prospective study. Study of Osteoporotic Fractures Research Group. Lancet 354:971-975; 1999.

[40] Krishnan, V.; Bryant, H. U.; Macdougald, O. A. Regulation of bone mass by Wnt signaling. J. Clin. Invest. 116:1202-1209; 2006.

[41] Fujii, H.; Hamada, Y.; Fukagawa, M. Bone formation in spontaneously diabetic Torii-newly established model of non-obese type 2 diabetes rats. Bone 42: 372-379; 2008.

[42] Lee, J. H.; Kim, H. N.; Yang, D.; Jung, K.; Kim, H. M.; Kim, H. H.; Ha, H.; Lee, Z. H. Trolox prevents osteoclastogenesis by suppressing RANKL expression and signaling. J. Biol. Chem. 284:13725-13734; 2009.

[43] Melhus, H.; Michaëlsson, K.; Holmberg, L.; Wolk, A.; Ljunghall, S. Smoking, antioxidant vitamins, and the risk of hip fracture. J. Bone Miner. Res. 14:129-135; 1999.

[44] Sahni, S.; Hannan, M. T.; Blumberg, J.; Cupples, L. A.; Kiel, D. P.; Tucker, K. L Protective effect of total carotenoid and lycopene intake on the risk of hip fracture: a 17-year follow-up from the Framingham Osteoporosis Study. J. Bone Miner. Res. 24:1086-1094; 2009.

[45] Sahni, S.; Hannan, M. T.; Gagnon, D.; Blumberg J.; Cupples, L. A.; Kiel, D. P.; Tucker, K. L. Protective effect of total and supplemental vitamin C intake on the risk of hip fracture-a 17-year follow-up from the Framingham Osteoporosis Study. Osteoporos. Int. in press, doi:10.1007/s00198-009-0897-y [Electronic publication ahead of print].

[46] Maggio, D.; Barabani, M.; Pierandrei, M.; Polidori, M. C.; Catani, M.; Mecocci, P.; Senin, U.; Pacifici, R.; Cherubini, A. Marked decrease in plasma antioxidants in aged osteoporotic women: results of a cross-sectional study. J. Clin. Endocrinol. Metab. 88:1523-1527; 2003.

[47] Pasco, J. A.; Henry, M. J.; Wilkinson, L. K.; Nicholson, G. C.; Schneider, H. G.; Kotowicz, M. A. Antioxidant vitamin supplements and markers of bone turnover in a community sample of nonsmoking women. J. Womens Health (Larchmt) 15: 295-300; 2006.

[48] Sahni, S.; Hannan, M. T.; Blumberg, J.; Cupples, L. A.; Kiel, D. P.; Tucker, K. L. Inverse association of carotenoid intakes with 4-y change in bone mineral density in elderly men and women: the Framingham Osteoporosis Study. Am. J. Clin. Nutr. 89: 416-424; 2009.

[49] Sahni, S.; Hannan, M. T.; Gagnon, D.; Blumberg, J.; Cupples, L. A.; Kiel, D. P.; Tucker K. L.; High vitamin, C. intake is associated with lower 4-year bone loss in elderly men. J. Nutr. 138:1931-1938; 2008.

[50] Hall, S. L.; Greendale, G. A. The relation of dietary vitamin C intake to bone minera density: results from the PEPI study. Calcif. Tissue Int. 63:183-189; 1998

[51] Morton, D. J.; Barrett-Connor, E. L.; Schneider, D. L.; Vitamin, C. supplement use and bone mineral density in postmenopausal women. J. Bone Miner. Res. 16: $135-140 ; 2001$

[52] Wolf, R. L.; Cauley, J. A.; Pettinger, M.; Jackson, R.; Lacroix, A.; Leboff, M. S.; Lewis, C. E.; Nevitt, M. C.; Simon, J. A.; Stone, K. L.; Wactawski-Wende, J. Lack of a relation between vitamin and mineral antioxidants and bone mineral density: results from the Women's Health Initiative. Am. J. Clin. Nutr. 82:581-588; 2005.

[53] Basu, S. Isoprostanes: novel bioactive products of lipid peroxidation. Free Radic. Res. 38:105-122; 2004.

[54] Kadiiska, M. B.; Gladen, B. C.; Baird, D. D.; Germolec, D.; Graham, L. B.; Parker, C. E.; Nyska, A.; Wachsman, J. T.; Ames, B. N.; Basu, S.; Brot, N.; Fitzgerald, G. A.; Floyd R. A.; George, M.; Heinecke, J. W.; Hatch, G. E.; Hensley, K.; Lawson, J. A.; Marnett, L. J.; Morrow, J. D.; Murray, D. M.; Plastaras, J.; Roberts II, L. J.; Rokach, J.; Shigenaga, M. K.; Sohal, R. S.; Sun, J.; Tice, R. R.; Van Thiel, D. H.; Wellner, D.; Walter, P. B.; Tomer, K. B.; Mason, R. P.; Barrett, J. C. Biomarkers of oxidative stress study II: are 
oxidation products of lipids, proteins, and DNA markers of CCl4 poisoning?Free Radic. Biol. Med. 38:698-710; 2005.

[55] Byberg, L.; Melhus, H.; Gedeborg, R.; Sundstrom, J.; Ahlbom, A.; Zethelius, B.; Berglund, L. G.; Wolk, A.; Michaelsson, K. Total mortality after changes in leisure time physical activity in 50 year old men: 35 year follow-up of population based cohort. BMJ 338:b688; 2009.

Bengt Östman

Department of Surgical Sciences, Section of Orthopaedics,

Uppsala University Hospital, Uppsala University, Sweden Ringerike Hospital, Section of Orthopaedics, Hønefoss, Norway

E-mail address: bengt.ostman@surgsci.uu.se.

Corresponding author. Department of Surgical Science,

Section of Orthopaedics, Uppsala University Hospital,

SE-751 85 Uppsala, Sweden. Fax: +4618508127.

Karl Michaëlsson

Liisa Byberg

Department of Surgical Sciences, Section of Orthopaedics, Uppsala University Hospital, Uppsala University, Sweden Uppsala Clinical Research Center, Uppsala University, Sweden
Johanna Helmersson

Samar Basu ${ }^{1}$

Oxidative Stress and Inflammation, Department of Public Health and Caring Sciences, Uppsala University, Sweden Center of Excellence-Inflammation, Uppsala University Hospital, Uppsala

University, Sweden

Rolf Gedeborg

Uppsala Clinical Research Center, Uppsala University, Sweden

Department of Surgical Sciences, Section of Anaesthesiology and Intensive Care, Uppsala University Hospital, Uppsala University, Sweden

Håkan Melhus ${ }^{1}$

Uppsala Clinical Research Center, Uppsala University, Sweden Department of Medical Sciences, Uppsala University, Sweden

1 April 2009

\footnotetext{
${ }^{1}$ These authors contributed equally.
} 